\title{
O Supremo Tribunal Federal e o dever de incluir: um vetor claro e inequívoco do direito à educação superior no Brasil
}

\section{The Supreme Court and the duty of inclusion: a clear and unequivocal vector of the right to higher education in Brazil}

\author{
Luiz Alberto David Araujo*
}

\begin{abstract}
RESUMO
A Convenção da ONU, sobre os Direitos das Pessoas com Deficiência, foi recebida como algo equivalente a uma emenda à Constituição, o que alterou sensivelmente a proteção desse grupo vulnerável. A Lei no 13.146/2015 (Estatuto da Pessoa com Deficiência) criou, na esteira da Convenção, diversas disposições buscando a inclusão desse grupo. Dentre elas, a obrigatoriedade de as escolas (em qualquer nível) receberem pessoas com deficiência sem qualquer recusa, além de não poderem cobrar nada mais por tal fato. O tema foi ao Poder Judiciário, patrocinado pela Confederação dos Estabelecimentos de Ensino Particular. A decisão do Supremo Tribunal Federal, com efeito vinculante, acabou com qualquer dúvida sobre o tema, fixando um vetor que deve ser seguido por todo o Estado brasileiro.

Palavras-chave: Deficiência. Inclusão. Convenção da ONU. Supremo Tribunal Federal. Obrigação de incluir.
\end{abstract}

\footnotetext{
ABSTRACT

The UN's Convention on the Rights of Persons with Disabilities was received in the Brazilian legal system as the equivalent of an amendment to the Federal Constitution, which has deeply modified the protection given to this special group so far. Law No. 13,146/2015 (the Disabled Person's Statute)

DOI: $10.1590 / 0104-4060.51045$

* Pontifícia Universidade Católica de São Paulo (PUC-SP). Departamento de Direito Público. Rua Monte Alegre, no 984. Perdizes, São Paulo, São Paulo. CEP: 05014-901. E-mail:
} ladafmda@pucsp.br 
has created several provisions aiming for the inclusion of this group. Among them, the obligation to all schools, in any level, to accept disabled people, without any refusal right, as well as not charging any extra fee for such acceptance. In response, the Confederação Nacional dos Estabelecimentos de Ensino (Schooling Institute's National Confederation, CONFENEN) decided to bring this matter to judicial courts. The decision of the Brazilian Supreme Federal Court, as a controlling authority (with binding effect decision)), quashed any doubts about this issue, establishing a guideline to be followed by any and all entities.

Keywords: Deficiency. Inclusion. UN Convention. Supreme Federal Court. Inclusion obligation.

\section{Introdução}

A Constituição da República Federativa do Brasil (BRASIL, 1988), dentre outras funções, teve o condão de resgatar a cidadania, restabelecendo um regime democrático, pondo fim ao sistema autoritário implantado em 1964. Sabemos todos que apenas uma Constituição não seria capaz de modificar a realidade. Ela foi seguida de um sentimento de mudança, caracterizado por diversos movimentos populares. O novo texto procurou assegurar os direitos da forma mais clara possível, muitas vezes, pecando por repetição. O texto é prolixo, repetitivo, como se fosse necessário repetir e repetir para termos a sensação de que os direitos estavam sendo protegidos. O Poder Judiciário se fortaleceu, recobrou suas garantias e iniciou um processo de garantia de direitos e liberdades.

Neste artigo, vamos procurar entender como o Poder Judiciário, especialmente o Supremo Tribunal Federal, participou do processo de inclusão, deixando marcado, de forma inequívoca, o direito à inclusão das pessoas com deficiência no sistema educacional. Para tanto, vamos procurar mostrar algumas características do Supremo Tribunal Federal ao analisar os termos da Lei n ${ }^{\circ}$ 13.146/2015 (BRASIL, 2015). No entanto, não podemos tratar do assunto sem mencionar a Convenção da ONU sobre os Direitos das Pessoas com Deficiência. O passo dado pelo Supremo Tribunal Federal é recente e ainda não lhe foi outorgada a importância devida.

Esse exercício vai nos colocar diante de temas como efeito vinculante, decisão abreviada, dentre outros, todos próprios do controle concentrado de constitucionalidade. A partir de tais características, procuraremos demonstrar que o sistema hoje tem o reconhecimento de um vetor inclusivo, não só pelo texto, mas pelo reconhecimento da Corte Suprema em uma decisão que tem características próprias. 


\section{A Constituição de 1988 e seus valores}

Podemos encontrar, na composição da Constituição Federal, normas que produzam efeitos distintos. De um lado, os princípios que trazem um vetor para a interpretação, funcionando com um condutor de valores para o intérprete, e, de outro lado, normas que têm um grau de concretude superior, tendo como função disciplinar determinado tema de forma direta.

O Título I, da Constituição Federal, intitulado "Dos Princípios Fundamentais", traz os valores principais que devem nortear a interpretação do texto. Assim, encontraremos expressões como "estado democrático de direito", "dignidade da pessoa humana", "valores sociais e do trabalho", "promover o bem de todos, sem preconceito...".

São normas que trazem consigo uma elevada valoração. Essa valoração permite que o intérprete busque nesses espaços as forças necessárias para conduzir o texto para a melhor interpretação possível. Quando se estiver interpretando, não podemos perder de vista tais valores, ou seja, a dignidade da pessoa humana e que é função do Estado promover o bem de todos, sem preconceito de origem, raça, sexo e cor.

Ora, esses comandos devem permear todo o sistema interpretativo, orientando, inclusive, a jurisprudência quando o tema for levado ao Poder Judiciário. Veremos isso aplicado de forma concreta um pouco adiante.

\section{A internalização dos instrumentos internacionais: a novidade do parágrafo $3^{\circ}$, do artigo $5^{\circ}$}

A Constituição Federal tratava, antes da Emenda $n^{0} 45$, os tratados internacionais de forma pouco clara. $\mathrm{O}$ artigo $5^{\circ}$, em seus parágrafos, afirmava que $\mathrm{o}$ sistema não se completava apenas com o texto da Constituição, mas com tratados internacionais assinados pelo Brasil. No entanto, não especificava em que hierarquia normativa tais tratados seriam recebidos no sistema. A discussão terminou quando o parágrafo $3^{\circ}$, do artigo $5^{\circ}$, foi incluído, de maneira que um tratado internacional de direitos humanos, votado na forma de uma emenda (com quórum de três quintos, em votação de dois turnos em cada Casa do Congresso Nacional), seria algo equivalente a uma emenda à Constituição. Estava aberta, de forma clara e inequívoca, a Constituição para os tratados de direitos humanos e sua implementação no Brasil, mas não na forma antiga, dúbia. Agora há comando claro e inequívoco que leva à incorporação do instrumento internacional com a altura de norma constitucional. 
Foi, portanto, a partir da Emenda Constitucional n 45 (BRASIL, 2004), de 30 de dezembro de 2004, que os tratados poderiam receber o status especial de norma constitucional. O sistema, assim, de forma bastante simples, permitiria tratados internacionais que, como sempre, ingressaram no sistema constitucional. Agora temos os tratados internacionais de direitos humanos. Esses entram no sistema se adotarem a fórmula do voto qualificado, como algo equivalente a uma emenda à Constituição. E, como trazem temas de direitos humanos, serão considerados cláusulas pétreas, ou seja, cláusulas imodificáveis. É verdade que o Congresso Nacional pode entender de não aplicar tal rito ao processo de aprovação de um tratado internacional de Direitos Humanos. Portanto, continua a possibilidade de o tratado internacional não ser votado como emenda. Dessa forma se manteria no sistema como uma postura supralegal, mas não constitucional. No entanto, adotado o rito especial e aprovado, ingressa no sistema constitucional como uma emenda à Constituição.

\section{Um único documento recebido pela forma do parágrafo $3^{\circ}$, do artigo $5^{\circ}$, da Constituição Federal}

No sistema brasileiro, há apenas um tratado internacional aprovado com esse rito até o momento. Trata-se da Convenção da ONU sobre os Direitos das Pessoas com Deficiência, que recebeu o referido status por força do Decreto Legislativo $\mathrm{n}^{0}$ 186 (BRASIL, 2008), de 9 de julho de 2008, e do Decreto Presidencial no 6.649 (BRASIL, 2009), de 25 de agosto de 2009. Com isso, ingressou como norma constitucional. E, como tal, deve ser analisado. Há, no entanto, pouco conhecimento desse instrumento. Poucos aplicadores do Direito o conhecem e o aplicam, como já dito, é único no sistema brasileiro. No entanto, a falta de conhecimento não pode ser motivo para deixarmos de aplicar um instrumento com esse grau de importância, nem pode servir de pretexto para a não aplicação; e aplicação com a valoração devida, qual seja, o texto tem importância de norma constitucional.

\section{A Convenção da ONU sobre os Direitos das Pessoas com Deficiência e sua hierarquia}

Que efeitos práticos têm o referido tratado internacional? Como devemos entender essa nova espécie introduzida no sistema brasileiro? Primeiramente, 
o tema deve ser visto sob a ótica da hierarquia. Estamos diante de algo equivalente a uma emenda à Constituição. Portanto, ele deve vincular o legislador infraconstitucional, a Administração Pública e todos os cidadãos. Pretender dar um tratamento de norma ordinária a uma emenda constitucional é um grave erro de interpretação. Portanto, quando se fala em tais normas, estamos falando em valores que devem permear toda a legislação infraconstitucional, os atos governamentais, e deve interferir diretamente nas relações privadas, mesmo que não haja participação do Estado. Há um dever de seguimento dos valores constitucionais, quer pelo poder público, quer pelos particulares.

O texto da Convenção é extenso e detalhado. Traz comandos ligados à vida independente, à honra, à dignidade das pessoas com deficiência e, especialmente, à vida em sociedade. O conceito de pessoa com deficiência é alterado substancialmente para abandonar o modelo médico, trazendo um parâmetro também de caráter ambiental.

Dentro da minúcia do documento, encontraremos o direito ao convívio social, que faz parte de uma das maneiras de se eliminar as barreiras para a inclusão da pessoa com deficiência.

Apenas para citar, os dispositivos constantes do artigo 24, Educação, tratam do ensino inclusivo como forma de direito fundamental. No item 5 , do mencionado artigo 24, o ajuste internacional (que é recebido como norma constitucional) cuida do ensino superior e determina a extensão dos princípios a tal nível de ensino. Ou seja, a pessoa com deficiência tem direito de ser respeitada em todos os níveis de ensino.

\section{O Estatuto da Pessoa com Deficiência (Lei no ${ }^{0}$ 13.146/2015)}

No intuito de dar cumprimento ao compromisso internacional assumido pelo Brasil, o Poder Legislativo tratou de elaborar a norma que iria (dentre outras formas) viabilizar a inclusão social da Inclusão da Pessoa com Deficiência ou Estatuto da Pessoa com deficiência, que recebeu o n ${ }^{\mathbf{0}} 13.146^{1}$.

A lei é extensa, detalhada e trata de diversos temas, modificando o Código Civil, o Código de Processo Civil, o Código do Consumidor, dentre outros diplomas legais. Sua matriz, como já afirmado, é a Convenção da ONU, logo,

1 Não é correto chamar o texto legal de Lei Brasileira da Inclusão. Há outras necessárias inclusões no Brasil. E, ao chamarmos assim, estamos excluindo a necessidade de tantas outras inclusões. Aliás, o Diário Oficial da União deu o nome de Lei Brasileira da Inclusão da Pessoa com Deficiência. 
norma recebida com status de norma constitucional. Não vamos nos deter na análise completa da lei, pois esse não é nosso objetivo. No entanto, importante destacar que a norma traz comando claro e inequívoco ligado à educação, pois trata do ensino inclusivo em seu artigo 27. A lei determina que haja um sistema educacional inclusivo, em que a pessoa com deficiência estude com outros indivíduos, de forma inclusiva e plena. Traça, no artigo 28 , os princípios que devem reger a inclusão no ensino. Tudo para deixar claro que há uma nova mentalidade e que a anterior não é mais aceita pelo sistema. Proíbe que a escola cobre tarifas extraordinárias dos alunos com deficiência, como determina o artigo 28 , parágrafo $1^{\circ}$ da referida lei; e, mais, proíbe que as escolas recusem alunos com deficiência. A providência salutar da norma tem como fundamento a inclusão da pessoa com deficiência, e, reflexamente, o desenvolvimento do convívio entre pessoa com deficiência e sem deficiência. É evidente que a inclusão encontra obstáculo na falta de um convívio, desde os tempos escolares, de coleguinhas de classe com deficiência e sem deficiência. Certamente, o arquiteto ou o engenheiro não iria planejar um edifício ou um auditório sem acessibilidade se tivesse incorporado tal valor como originário de sua formação básica. É evidente que teríamos um mundo mais acessível. No entanto, tal convívio (em linhas gerais) ainda não era incentivado pelo sistema normativo, agora é. Trata-se dos artigos 27 e 28 da lei mencionada.

\section{A ação direta de inconstitucionalidade $n^{0} \mathbf{5 . 3 5 7}$}

O sistema de proteção constitucional vigente permite a discussão de uma lei sob o enfoque da constitucionalidade de duas maneiras. A via de exceção, em que o indivíduo vai discutir seu caso concreto perante o Poder Judiciário e a decisão que reconhece ou não a constitucionalidade só terá efeitos entre as partes; e a via concentrada, em que determinados autores, elencados no artigo 103 da Constituição Federal, podem discutir, com efeitos erga omnes, ou seja, com efeito para todos a constitucionalidade de uma norma. Nesse caso, a ação é ajuizada perante o Supremo Tribunal Federal.

Não vamos apresentar aqui, porque não é o escopo do trabalho, as normas que podem ser objeto da ação direta de inconstitucionalidade, um dos instrumentos do mencionado controle concentrado. Mas podemos, desde logo, afirmar que a decisão desse processo tem efeito vinculante, ou seja, decidido pelo Supremo Tribunal Federal que a norma é constitucional ou não, a decisão se aplica ao Poder Judiciário como um todo, obrigando o juiz a tomar decisões 
no sentido determinado pela Suprema Corte e os Poderes Públicos a seguir a orientação da Corte.

Não há mais espaço para desobediência da decisão. O Supremo Tribunal Federal decide e, salvo por motivos relevantes de mudança da realidade, pode, em raríssimos casos, rever tal decisão. Essa advertência é importante, porque o resultado da decisão do Supremo Tribunal Federal será objeto de ponderação adiante.

Dentro dessa via, foi ajuizada a ação direta de inconstitucionalidade (ADI) que recebeu o $\mathrm{n}^{\circ} 5.357$ (BRASIL, 2016).

Vamos falar brevemente de tal processo.

A Confederação Nacional dos Estabelecimentos de Ensino (Confenem) ajuizou uma ADI visando à declaração de inconstitucionalidade de dispositivos do Estatuto da Pessoa com Deficiência. A petição inicial afirmava que, em homenagem ao direito de propriedade, os estabelecimentos de ensino privado não estariam submetidos ao dever de incluir, constante da Lei (e da Convenção). Afirma que este seria um dever do Estado e que as novas regras iriam representar novos custos que seriam repassados aos alunos com prejuízos gerais. Atacam, portanto, os artigos 28, parágrafo único, e o artigo 30, especialmente, a expressão "privada" constante do dispositivo legal. Insurge-se, em linhas gerais, contra a obrigatoriedade de receber alunos com deficiência e do envolvimento, pela lei, das escolas privadas. Os argumentos podem ser obtidos na petição inicial, que pode ser encontrada no sítio do Supremo Tribunal Federal. Não cabe aqui criticar o tom da petição inicial, mas uma leitura breve e rápida já permite verificar o distanciamento entre a petição inicial e os dizeres da Constituição Federal, da Convenção da ONU e do Estatuto da Pessoa com Deficiência².

O processo pedia a medida liminar, providência que suspenderia a vigência da norma até que o processo fosse definitivamente julgado. Para tanto, deveria haver um perigo na mora e o vestígio do bom direito. A petição inicial procurava demonstrar que havia um vestígio do bom direito e que a demora iria prejudicar as escolas, especialmente porque estavam planejando o próximo semestre.

Caberia ao Relator acolher o pedido de liminar, levando, em seguida, a decisão para o plenário do Supremo Tribunal Federal.

O processo foi distribuído ao ministro Edson Fachin.

Logo que se propagou a notícia do ajuizamento do processo, diversas instituições da sociedade pretenderam participar do feito na qualidade de amicus curiae. A figura processual permite que uma associação ou um grupo possa

2 Petição inicial encontrada no site: http://redir.stf.jus.br/paginadorpub/paginador.jsp?doc$\mathrm{TP}=\mathrm{TP} \&$ docID $=9058845 \& \mathrm{ad}=\mathrm{s} \# 2 \% 20-\% 20 \mathrm{Peti} \% \mathrm{E} 7 \% \mathrm{E} 3 \mathrm{o} \% 20$ inicial $\% 20-\% 20$ Peti $\%$ E7\%E3o\%20 inicial $\% 201$ 
participar do processo, colaborando com o seu desenvolvimento, desde que demonstre seu interesse na causa. É a regra do parágrafo $2^{\circ}$, do artigo $7^{\circ}$, da Lei $n^{\circ}$ 9.868/1999 (BRASIL, 1999). Foram vários os interessados. Isso, de alguma forma, legitima a discussão do feito. Diversos interesses estiveram presentes. Todos os movimentos podem ser obtidos junto ao site do Supremo Tribunal Federal, assim como as instituições que pediram sua inclusão no processo.

Os pedidos de inclusão na qualidade de amicus curiae foram muitos, o que revela que o tema teve ampla discussão.

O pedido de liminar foi apreciado pelo ministro Edson Fachin.

Em um longo e muito bem lançado despacho, o ministro indeferiu o pedido de liminar. Deixou claro que não havia, a seu ver, nenhuma inconstitucionalidade. Ao contrário, havia um claro dever de incluir. Rejeitou (ainda na apreciação da liminar) o tema de que as escolas privadas não estariam obrigadas a se submeter à lei porque a Constituição asseguraria o direito de propriedade. A decisão, que tem grande importância, como será visto adiante, pode ser encontrada na sua íntegra no sítio do Supremo Tribunal Federal ${ }^{3}$.

Entendeu o ministro Edson Fachin que, ao contrário do que alegava a autora, a ação direta de inconstitucionalidade, o direito à inclusão social das pessoas com deficiência estava claro e inequívoco. Tanto que indeferiu a liminar em belo e didático despacho. Conforme determina a legislação ordinária, pediu pauta para que o Colegiado do Supremo Tribunal Federal apreciasse a matéria, ratificando ou não seu entendimento. A decisão causou uma grande sensação de alegria a todos que lutam pela inclusão da pessoa com deficiência. Não só pela qualidade do texto, sensível e muito apurado judicialmente, mas também pela firmeza com que apreciou o tema. A decisão (ainda parcial e precária) do ministro relator deixou evidente que seu entendimento era de rejeitar o pedido. A escola estaria obrigada a receber pessoas com deficiência. Não era dever do Estado, mas de todos do Estado. Incluídos aí, certamente, os vinculados à autora, estabelecimentos de ensino privados.

\section{a) O amicus curiae (o amigo da Corte): o envolvimento da sociedade}

A notícia do ajuizamento da ação direta de inconstitucionalidade, atacando a jovem lei, pois criada a pouco, trouxe a preocupação da sociedade. Diversas

3 Decisão liminar encontrada no sítio do STF: http://www.stf.jus.br/portal/jurisprudencia/ listarJurisprudencia.asp?s1=\%28ADI $\% 24 \% 2 \mathrm{ESCLA} \% 2 \mathrm{E}+\mathrm{E}+5357 \% 2 \mathrm{ENUME} \% 2 \mathrm{E} \% 29+\mathrm{NAO}+$ $\mathrm{S} \% 2 \mathrm{EPRES} \% 2 \mathrm{E} \&$ base=baseMonocraticas\&url=http://tinyurl.com/qj8615c 
entidades, associações, fizeram questão de participar do processo, pedindo seu ingresso como amicus curiae, na forma do parágrafo $2^{\circ}$, do artigo $7^{\circ}$, da Lei ${ }^{\circ}$ 9.868/1999. Isso teve um significado muito importante, revelando que o tema está sendo observado e que há muitos outros interessados na boa aplicação do Direito, além da Confederação autora da ação. A análise da ficha perante o Supremo Tribunal Federal mostra uma clara manifestação da sociedade. Todos tinham interesse em ver o tema discutido. Como já mencionamos, os efeitos da decisão seriam vinculantes, por isso, a importância. Estávamos diante de uma decisão que iria colocar o Brasil em um caminho mais inclusivo ou deixar a cada instituição privada se aceitava ou não uma pessoa com deficiência, aumentando a exclusão e o processo de afastamento do núcleo social desse grupo de pessoas.

Não poderíamos deixar de mencionar, portanto, o grande número de associações e demais entidades que se interessaram pelo tema, contratando seus advogados, fazendo-se representar no processo. Isso releva, desde logo, a importância do tema e a extensão da decisão, que iria fixar os caminhos do ensino inclusivo no Brasil. A sociedade se mobilizou, causando, de certa forma, até um tumulto no processo, diante de tantos pedidos de participação na lide. Era a vontade popular, ligada a associações, grupos, instituições, que queriam deixar sua manifestação pela rejeição do pedido de inconstitucionalidade, permitindo que o processo de inclusão tomasse seu caminho natural.

\section{A decisão do Supremo Tribunal Federal: abreviada e vinculante e possível de reclamação}

Atendendo ao regulamento processual civil, o ministro Edson Fachin pediu pauta para apresentar seu voto ao Supremo Tribunal Federal em sua plenária. A decisão, que entendeu que a norma era constitucional, deveria ser referendada pelo Plenário da Corte, afastando a pretensão da Confenem. A Corte poderia ratificar a decisão, rejeitar a decisão ou, aproveitando-se de um dispositivo legal, abreviar o feito, acolhendo a decisão liminar e dando como terminado o processo.

O Supremo Tribunal Federal, entendendo que a medida liminar havia sido bem apreciada, que não merecia qualquer reparo e diante da convergência de interesses, utilizaram-se da possibilidade de converter o julgamento da medida liminar como decisão definitiva, pondo fim ao processo, tudo conforme o artigo 12, da Lei $\mathrm{n}^{\mathrm{o}}$ 9.868/99. Com a ausência justificada de um ministro e um voto contrário, nove ministros votaram a favor da manutenção da norma no sistema, ratificando o belo voto do ministro relator. 
O Supremo Tribunal Federal, portanto, sem qualquer dúvida e com pequena divergência (um voto apenas), entendeu, por nove votos a um, que o tema não merecia qualquer reparo. Primeiro, a liminar indeferida, segundo o apoio da sociedade querendo participar do processo. Agora, no terceiro momento, uma vitória esmagadora que abreviou o feito, tamanha a convergência de interesses da Corte!

Não vamos nos esquecer de que a decisão tem efeito vinculante, ou seja, obriga a todos os juízes do Brasil e os órgãos públicos que não poderão deixar de cumprir a decisão. A autora tentou obter um efeito vinculante; não conseguiu. Agora, o efeito é exatamente o contrário. Nenhum juiz do Brasil ou órgão do Poder Público pode deixar de aplicar a norma que foi considerada constitucional pela Corte Suprema!

O julgamento definitivo encontra-se no site do Supremo Tribunal Federal. Salvo o voto isolado contrário, foram nove ministros acolhendo a tese e uma ausência justificada ${ }^{4}$.

O Supremo Tribunal Federal, portanto, deixou de forma clara e inequívoca que o dever de incluir está presente, vigente, no sistema, exatamente de acordo com a Constituição Federal. Participaram do processo, reforçando ainda mais a sua legitimidade, diversas associações que tiveram seu papel reconhecido como amicus curiae.

A decisão do Supremo Tribunal Federal é uma diretriz clara e inequívoca quanto ao processo de inclusão. Não só decidiu ainda na fase de liminar, como facultava a lei processual, como decidiu por maioria esmagadora (nove a um). Tudo acompanhado por diversas associações que fizeram questão de revelar seu interesse pelo feito.

A decisão, portanto, é uma luz direta, obrigatória (porque a decisão é vinculante) para aqueles que entendem que a tarefa de incluir é apenas do Estado. A decisão envolve todos os níveis de ensino, porque a decisão não teve o condão

4 Texto do julgamento da ADI n 5.357 do Supremo Tribunal Federal. Decisão: O Tribunal, por unanimidade, deliberou converter o julgamento do referendo da cautelar em julgamento de mérito, julgando, por maioria, improcedente a ação direta, vencido, no ponto, o Ministro Marco Aurélio, que a julgava parcialmente procedente, tudo nos termos do voto do Relator. Ausente, justificadamente, o Ministro Celso de Mello. Falaram, pela requerente Confederação Nacional dos Estabelecimentos de Ensino - CONFENEN, o Dr. Roberto Geraldo de Paiva Dornas; pela Advocacia-Geral da União, a Dra. Grace Maria Fernandes Mendonça, Secretária-Geral de Contencioso; pelo amicus curiae Federação Nacional das Apaes - FENAPAES, a Dra. Rosangela Wolff Moro; pelo amicus curiae Conselho Federal da Ordem dos Advogados do Brasil o Dr. Oswaldo Pinheiro Ribeiro Júnior, e, pelo Ministério Público Federal, a Dra. Ela Wiecko Volkmer de Castilho, Vice-Procuradora-Geral da República. Presidiu o julgamento o Ministro Ricardo Lewandowski. Plenário, 09.06.2016. Disponível em: http://www.stf.jus.br/portal/processo/verProcessoAndamento. asp?incidente $=4818214$. Acesso em: 23 ago. 2016. 
de restringir. Ao contrário, foi ampliativa, dando à pessoa com deficiência um excelente instrumento de defesa. Agora o tema da educação inclusiva já tem manifestação do Supremo Tribunal Federal. Rejeitou de forma inequívoca o pleito discutido na $\mathrm{ADI} \mathrm{n}^{\mathrm{0}} 5.357 \mathrm{e}$, mais do que isso, com seus efeitos vinculantes, emitiu diretriz clara ao Poder Judiciário, como um todo, e a toda a Administração Pública - federal, estadual e municipal - para que adote tal postura em relação a todos os níveis de ensino, incluindo aí, o nível superior, como é cediço.

\section{REFERÊNCIAS}

BRASIL. Constituição da República Federativa do Brasil. Brasília: Senado Federal, 1988.

BRASIL. Decreto Legislativo $n^{\circ} 186$, de 2008. Aprova o texto da Convenção sobre os Direitos das Pessoas com Deficiência e de seu Protocolo Facultativo, assinados em Nova Iorque, em 30 de março de 2007. Diário Oficial da União, 31 jul. 2008.

BRASIL. Decreto Legislativo no 6.949 , de 25 de agosto de 2009. Promulga a Convenção Internacional sobre os Direitos das Pessoas com Deficiência e seu Protocolo Facultativo, assinados em Nova York, em 30 de março de 2007. Diário Oficial da União, 26 ago. 2009.

BRASIL. Lei n ${ }^{\circ} 9.868$, de 10 de novembro de 1999. Dispõe sobre o processo e julgamento da ação direta de inconstitucionalidade e da ação declaratória de constitucionalidade perante o Supremo Tribunal Federal. Diário Oficial da União, 11 nov. 1999.

BRASIL. Lei no 13.146, de 6 de julho de 2015. Institui a Lei Brasileira de Inclusão da Pessoa com Deficiência (Estatuto da Pessoa com Deficiência). Diário Oficial da União, 7 jul. 2015.

BRASIL. Emenda Constitucional no 45, de 30 de dezembro de 2004. Diário Oficial da União, 31 dez. 2004.

BRASIL. Supremo Tribunal Federal. ADI 5.357 - Ação Direta de Inconstitucionalidade. Acompanhamento Processual. Disponível em: <http://www.stf.jus.br/portal/processo/ verProcessoAndamento.asp?incidente=4818214>. Acesso em: 23 ago. 2016.

Texto recebido em 05 de março de 2017. Texto aprovado em 20 de março de 2017. 
